\title{
obituary
}

\section{DrThomas Freeman}

Thomas Freeman had a long and distinguished career as both a psychoanalyst and a general psychiatrist. He wrote several books and over a hundred papers related to the study of psychoses. Those who wish to fully appreciate the breadth of his academic contributions are referred to the Obituary in The Times (31 May 2002), written by Dr Clifford Yorke.

Dr Freeman worked for over 35 years as a consultant psychiatrist, first in Glasgow and later in Northern Ireland. He also worked closely with Anna Freud, at the Hampstead Child Therapy Clinic in London. He adapted her schema for diagnostic assessment of childhood psychological disorders to patients with psychotic disorders.

For those unfamiliar with his work, his paper 'Psychotherapy and General Psychiatry - Integral or Separable?' (1985), published in the first volume of Psychoanalytic Psychotherapy, presents his views in an easily readable format. His book, The Psychoanalyst in Psychiatry (1998), provides a detailed exposition of his approach.

Dr Freeman was concerned at the widening divide in approach to neurosis and psychosis within general psychiatry. While a psychotherapeutic approach of talking to the patient was regarded as appropriate for neuroses, it was not for psychoses, where increasing prescription of medication was becoming predominant.

Tom Freeman held that psychotherapy was an integral part of psychiatric practice, as a means of participating in, as well as observing the patient's subjective experience. He was concerned that psychotherapy was being gradually divorced from general psychiatry, with the loss of a clinical tradition in psychiatry to relate to your patient.

He viewed schizophrenia and organic psychoses in terms of a dissolution of the personality, with regression to earlier phases of development, sometimes under stress, with the mind then working in less sophisticated ways. However, this did not mean, he argued, that one should not share with the patient their experience

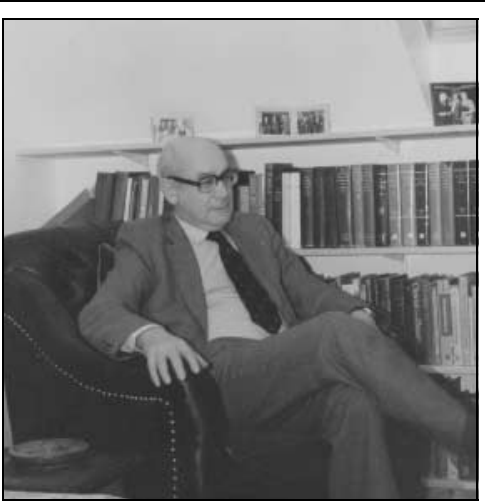

while they were going through it and relate to them accordingly.

He utilised a famous late nineteenth century neurologist Hughlings Jackson's theory of the evolution and dissolution of the nervous system as a template for constructing his model of approach to functional and organic psychoses. The end product of a developmental process would be the adult personality. In psychoses, the loss of developmental achievements would lead to the negative symptoms. Less developed forms of mental life would come to the fore, with the dissolution of the adult personality and these would represent the positive symptoms of the illness.

In this more primitive way of functioning, in schizophrenia, the patient would use the same ways as a young child replacing his real parents with imaginary parents more to his liking as in Freud's description of family romances. Sibling rivalries also would feature in the phantasies. Freeman underlined two central phenomena dominating this way of functioning, appersonation and transivitism, terms used by Bleuler in his description of schizophrenia. Appersonation meant that you assimilated physical and mental features of orphans, while transivitism meant attributing to others physical and mental aspects of the self in relation to wish fulfilments.

Freeman developed his theories within a classical Freudian framework, so that his style contrasts to contributions to psychosis from Kleinian analysts, such as
Rosenfeld and Bion. However, the main point that Freeman repeatedly made was that one needed to listen carefully to the patient so that one could then relate to them at the level of their current experiences.

Tom Freeman's seminal work on psychosis has acted as an inspiration, for those analysts who have followed him in the field, to resist a gap being created between neurosis and psychosis, where only the former become candidates for psychotherapeutic engagement. I remember Dr Freeman once saying to me at a conference he arranged in Northern Ireland, that the difference between ourselves and organically-based psychiatrists, was that they knew what was going on. We had not the faintest idea, so we had to listen to our patients to see if they could help us!

Dr Freeman, although expressing his own views in a clear and firm way, was a modest man. As a result, his achievements may not have been as widely appreciated, as they should have been, outside of analytic circles. His achievements in later life were quite remarkable. After retiring from the NHS, as the sole psychoanalyst in Northern Ireland, he single-handedly set up a training scheme for psychoanalytic psychotherapy. He both analysed and supervised the candidates, as well as arranging for further supervision in England.

As a result of his endeavours, in 1989, the Northern Ireland Association for the Study of Psychoanalysis was set up and continues to flourish. It retains a particular interest in the analytic contribution in relating to psychosis. The Association acts as an ongoing testament to his lifelong input to the field of psychosis.

FREEMAN, T. (1985) Psychotherapy and General Psychiatry - Integral or Separable? Psychoanalytic PsychotherapyVol 1 No 1, pp. 19-29.

- (1998) The Psychoanalyst in Psychiatry. Karnac London.

Obituaries. Thomas Freeman. TheTimes, 31 May 2002, p. 39.

\section{Richard Lucas}

